\title{
Social Network Sites Effectiveness from EFL Students' Viewpoints
}

\author{
Sulaiman Alnujaidi ${ }^{1}$ \\ ${ }^{1}$ College of Languages and Translation, Al-Imam Muhammad Ibn Saud University, Riyadh, Saudi Arabia \\ Correspondence: Sulaiman Alnujaidi, English Department, College of Languages and Translation, Al-Imam \\ Muhammad Ibn Saud University, P.O. Box 5701, Riyadh, 11432, Saudi Arabia. Tel: 966-598-615-007. E-mail: \\ sulaiman_alnujaidi@yahoo.com
}

Received: November 9, 2016 Accepted: December 5, 2016 Online Published: December 8, 2016

doi: 10.5539/elt.v10n1p39

URL: http://dx.doi.org/10.5539/elt.v10n1p39

\begin{abstract}
This study investigated the relationship between EFL students' experience, attitudes, perceptions, and expectations toward the effectiveness of Social Network Sites (SNS), namely, Facebook, Twitter, YouTube, Instagram, Flickr, Classmates, Academica, MySpace, English baby, and Google+, in English language learning. A survey of 103 participants from different higher education institutions in Saudi Arabia was conducted. The study's results revealed that the participants had an average SNS experience. The findings also indicated that participants had overall positive attitudes, perceptions, and expectations toward SNS. In addition, the correlations between experience and attitudes, and experience and expectations were statistically significant. Data analysis also showed that the correlations between attitudes and perceptions, attitudes and expectations, and perceptions and expectations were statistically significant. However, experience did not significantly correlate with perceptions. The findings also indicated that the model of the three variables (attitudes, perceptions, and expectations toward SNS) predicting the variable (experience in SNS) was statistically significant: The significant predictor was expectations.
\end{abstract}

Keywords: EFL, ESL, TEFL, SNS

\section{Introduction}

Social Network Sites (SNS), such as Facebook, Twitter, YouTube, Instagram, and MySpace, have attracted millions of users, many of whom have integrated these sites into their daily practices, and allowed users to connect based on shared interests, political views, or activities (Clarkson, 2013). Some SNS tools target diverse audiences, while others are based on shared linguistic, racial, sexual, religious, or nationality-based identities (Boyd \& Ellison, 2007). The benefit of SNS entails the ease of access through a personal computer and portable devices such as mobile phones, PDAs, smart phones, and MP3/MP4 players. Mobile devices have provided language learners with real-time experience, spontaneous interaction, and simultaneous integration (Duman, Orhon, \& Gedik, 2015).

According to Boyd and Ellison (2007), SNS allow individuals to “(1) construct a public or semi-public profile within a bounded system, (2) articulate a list of other users with whom they share a connection, and (3) view and traverse their list of connections and those made by others within the system" (p. 1). Duffy (2011) identified five common features of SNS: "a user can (1) create a profile, (2) find peers online, (3) publicly erect or confirm peer connections, (4) collaborate to share content, and (5) form online communities" (p. 286).

\subsection{Purpose of the Study}

Although the potential of SNS is much enthused over, there is scarcity of evidence-based research on their use as instructional tools for L2 learners or on learner's perceptions of the usefulness of SNS (Liu et al., 2013). As attitudes and perceptions can influence the stakeholders' use of SNS, especially from the learners' viewpoints, it is critical to study and understand carefully EFL students' attitudes and perceptions on SNS effectiveness in their learning process. Given the scarcity of research on this topic, this study addressed the following research questions:

1) What are the experience of EFL students in SNS?

2) What are the attitudes, perceptions, and expectations of EFL students toward the effectiveness of SNS in English language learning? 
3) Is there a statistically significant relationship between EFL students' experience, attitudes, perceptions, and expectations toward the effectiveness of SNS in English language learning?

\subsection{Significance of the Study}

This research study aims to investigate the relationship between EFL students' experience, attitudes, perceptions, and expectations toward the effectiveness of SNS in English language learning. The results of this study can provide valuable insights into how social networking technologies function as effective teaching and learning tools for ESL language learners when developing their language skills (listening, speaking, reading, and writing).

\section{Literature Review}

\subsection{Advantages of SNS}

Many studies have been conducted to discuss and measure the influence of SNS effectiveness and integration in language learning. The immense popularity of social networking has created new opportunities for language learners to interact in authentic ways that were previously difficult to achieve (Chartrand, 2012). SNS contribute to fostering positive relationships among students and providing many opportunities for interaction with peers, instructors, and native speakers (Blattner \& Fiori, 2009). Liu et al. (2015) examined four selected SNS from ESL instructors and learners, evaluated their ease of use, and identified their potential uses as teaching and language learning tools, which was reflected in their findings that demonstrated positive potential of these sites. Lai, Yeung, and $\mathrm{Hu}$ (2016) examined students' and teachers' perceptions of the specific roles teachers may play in promoting autonomous language learning using technology outside the classroom. They found that students expected teachers to play a greater role in supporting their autonomous learning with technology by recommending a variety of technological resources; whereas, teachers expected to play a minimal role due to their overestimation of students' capacities and their concern over their limited abilities to provide such support. These findings advocate teachers' increased awareness toward building essential knowledge and skills to meet the multiple roles required of them in supporting students' autonomous language learning using technology.

Current research on the use of Web 2.0 technologies in second language (L2) learning revealed that "second language learning/acquisition research has been experiencing a paradigm shift: from a cognitive orientation to a social orientation, from classroom contexts to naturalistic settings, from an acquisition metaphor to a participation metaphor, and from L2 learning to L2 use" (Wang \& Vasquez, 2012, p. 413). Hence, the application of Web 2.0 technologies in many L2 learning contexts has transformed pedagogy, curriculum design, language learning conceptions, and even research in this field. Mobile technologies are so intriguing because they provide the flexibility to move between indoors and outdoors and across formal and informal settings. These unique characteristics make them highly effective in supporting small group collaborative learning, and they enable learning to be more directly connected with real world experiments and situations (Kukulska-Hulme, 2009). Therefore, students prefer to "go mobile" over the PC as their learning tool (Bibby, 2011).

ESL teaching that incorporates SNS was found to "broaden students' knowledge, increase their motivation, and build confidence in learning ESL writing" (Yunus, Salehi, \& Chenzi, 2012, p. 16). Both teachers and students should be equipped with technical skills in order to maximize on SNS potentials (Yunus et al., 2012). On students' perceptions toward SNS use in English classes, Kikuchi and Otsuka (2008) found that SNS facilitated dynamic communication inside and outside the classroom, created a sense of community and belonging, provided authentic exposure to English, and stimulated motivation to learn English in an authentic fashion. Alm (2006) argued that while language-learning software and online learning programs could only assist in the acquisition of lower thinking skills (e.g., basic vocabulary), SNS enable language learners to acquire higher proficiency skills with use of complex structures that involve conceptual learning. Many EFL writing, listening, vocabulary, and research activities can be initiated and incorporated through Twitter because "Twitter not only provides an alternative medium through which to improve students' written communication skills, but also their analytical, collaborative, and social networking skills" (Mork, 2009, p. 51).

Facebook groups can also be effective in teaching ESL writing as students could learn new vocabularies from reading the group members' comments, and the spell-check feature helps reduce spelling errors (Melor \& Salehi, 2012). Facebook-integrated instruction can significantly enhance students' interest and motivation (Ru-Chu, 2011). Furthermore, students perceive Facebook as a useful and meaningful tool to support, enhance, and/or strengthen their English learning (Kabilan, Ahmad, \& Abidin, 2010). Mahmud and Ching (2012) described the incorporation of Facebook as a pedagogical means in the ESL settings and reported the students' positive perceptions on this social intermediary to enhance their L2 learning; conclusively, Facebook had generally enhanced their L2 skills, such as reading and writing, expanded their social circles, improved their communication skills, and minimized their apprehensions when using the language among their peers. 
Kho and Chuah (2012) used Facebook as a tool to facilitate students' discussion activity. Their findings endorsed English teachers' incorporation of Facebook or other similar online social networks, such as Blogs and Twitter, in their teaching activities to make lessons more fun and interactive. YouTube's online technology and streaming videos have also generated tremendous interest and motivation in EFL students (Hamilton, 2010). YouTube has a number of ESL-related videos, posted by teachers and students, which can be incorporated into the ESL classroom to promote student discussions (Chartrand, 2012).

\subsection{Disadvantages of SNS}

Albeit SNS have several remarkable features, they were reported to waste time, minimize socializing, encourage plagiarism, violate privacy, spread harmful and unreliable information, create fake characters, and cause distraction, disturbance, gossiping, and addiction (Vural, 2015). For example, one of the drawbacks that is often discussed when using Facebook in the teaching and learning context is its privacy violation. Students get more confident in their English writing skills and become more open to talk about their private lives online, which may lead to identify theft. Therefore, teachers and students need to discuss some guidelines and agree on some rules before they start using it (Chartrand, 2012).

Likewise, instructors should make sure that the YouTube video clips are appropriate, accurate, and credible. The video clips selected for their students should not discriminate against age, gender, race, disability, and religious orientation. Some video clips may require guidance from the teachers. Video clips with provocative language and/or nudity should be avoided. Also, the video clips should accurately address the skills that are targeted to be learned by students. Instructors should only use video clips from reliable sources as well as consider copyright restrictions (Burke, Snyder, and Rager, 2009).

Although Twitter has plenty of advantages as a teaching and learning tool, it also poses some disadvantages. Tweeting could be too distracting, time-consuming, and addictive for some students. Tweeting could also lead to spreading rumors and spams as well as violating student's privacy. To avoid its limitation of 140 characters, some students may ignore some grammatical rules and use incorrect grammar (Grosseck \& Holotescu, 2008).

Therefore, teachers, instructors, and institutions should address and minimize the negative aspects that are usually associated with using SNS in the teaching and learning context.

\section{Method}

\subsection{Research Design}

To investigate this study's research questions, a descriptive-correlational research design was employed "to learn about the relationship among variables and to make predictions based on an understanding of the relationship" (Johnson \& Christensen, 2000, p. 26) and to "determine relationships among two or more variables without necessarily inferring causality" (Swanson \& Holton, 1997, p. 70).

\subsection{Definition of Constructs}

This study used four constructs (experience, attitudes, perceptions, and expectations) in order to investigate their relationship as they infleucne the participants's viewpoints toward SNS.

Experience was defined as "practical knowledge, skill, or practice derived from direct observation of or participation in events or in a particular activity" (Merriam Webster Dictionary). Cambrideg Dictionary provided a similar definition for experience as "the process of getting knowledge or skill from doing, seeing, or feeling things". For the purpose of this study, experience was viewed as knowledge and mastery of SNS tools.

Attitude was defined as "a relatively enduring organization of beliefs, feelings, and behavioral tendencies towards socially significant objects, groups, events or symbols" (Hogg \& Vaughan, 2005, p. 150). Eagly and Chaiken (1993) introduced a similar conceptualization as "a psychological tendency that is expressed by evaluating a particular entity with some degree of favor or disfavor" (p. 1). Finally, Maio, and Haddock (2010, p. 3 ) viewed attitude as an overall evaluation of an object that is based on cognitive, affective, and behavioral information. This study adopted the definition of perception proposed by Johnson (2010) as "an internal factor when comparing interpersonal traits such as one's feelings or motivation toward an innovation" (p. 51).

Perception was defined as "the process whereby people select, organize, and interpret sensory stimulations into meaningful information about their work environment." (Rao \& Narayan, 1998) A similar definition of perception was proposed by Michener, DeLamater and Myers (2004) as "constructing an understanding of the social world from the data we get through our senses." Likewise, Myers (2004) defined perception as "the process of organizing and interpreting sensory information, enabling us to recognize meaningful objects and events" (p. 148). This study adopted the definition of perception proposed by Johnson (2010) as "an external 
factor which concerns one's view, understanding, belief, or reaction to an innovation" (p. 51).

Expectation was defined as "what one anticipates or looks forward to as a result of the previous experience" (Simonson, 1995: 171). This study adopted the definition of expectation proposed by Johnson (2010) as "one's belief, understanding, or conception about an innovation" (p. 51).

\subsection{Participants}

Data was collected from a sample of EFL students $(\mathrm{N}=103)$ in several Saudi higher education institutions that included male, female, Saudi, and non-Saudi participants in different college levels and majors. Analysis of participants' demographics (gender, age, nationality, \& major) revealed that that $57.3 \%$ of them were males and $42.7 \%$ were females. The majority $57.3 \%$ of the participants were aged between $18-22$ years old, and the majority of participants $79.6 \%$ were Saudi nationals. The analysis also showed that the majority $36.9 \%$ of participants were in their Preparatory Year, whereas the least participants, $5.8 \%$, were in the second year of college. As for major, the majority of participants $28.2 \%$ were Linguistics major.

\subsection{Data Collection}

The data collection instrument was a survey questionnaire for obtaining information about attitudes and perceptions (Johnson \& Christensen, 2000). This study used the "Information and Communication Technology (ICT) Use in English Teaching," adapted from the University of Warwick: ICT was replaced with SNS to fit this study's scope. The questionnaire comprised five parts with 63 items. The first part consisted of five items focusing on the participants' demographics. The second, third, and fourth parts consisted of 10 Likert-scale items designed to identify the participants' experience in SNS, 10 Likert-scale items to identify the participants' attitudes toward SNS, and 20 Likert-scale items to identify the participants' perceptions toward SNS, respectively. The fifth part comprised 18 Likert-scale items to identify the participants' expectations toward SNS.

\subsection{Validity and Reliability}

The "ICT Use in English Teaching" has been widely used in past studies investigating technology adoption and integration; however, for this study, ICT was replaced with SNS. The Cronbach's alpha reliability coefficients of the instrument indicated a high internal consistency, as described in Table 1.

Table 1. Cronbach's alpha reliability coefficients

\begin{tabular}{lllll}
\hline Variable & Number of Items & Mean & Std. Deviation & Alpha \\
\hline Experience & 10 & 29.69 & 8.47 & 0.836 \\
Attitude & 10 & 34.66 & 5.77 & 0.750 \\
Perceptions & 20 & 78.87 & 13.10 & 0.937 \\
Expectations & 18 & 69.06 & 11.69 & 0.916 \\
ALL & 58 & 211.99 & 29.70 & 0.941 \\
\hline
\end{tabular}

\section{Results and Discussion}

\subsection{Experience of EFL Students in SNS}

To answer the $1^{\text {st }}$ research question, participants were asked 10 items that were designed to identify their experience in some popular SNS. Figure 1 revealed participants' overall average experience in SNS $(\mathrm{m}=2.97$, $\mathrm{SD}=1.32$ ). Youtube (4.27) was ranked the highest, followed by Twitter (3.81), Instagram (3.50), and Facebook (3.47). The participants rated average experience for Google Plus+ (2.84), Classmates (2.72), English baby (2.51), Academia (2.35), and Flicker (2.22); however, they rated low experience for MySpace (1.99). 


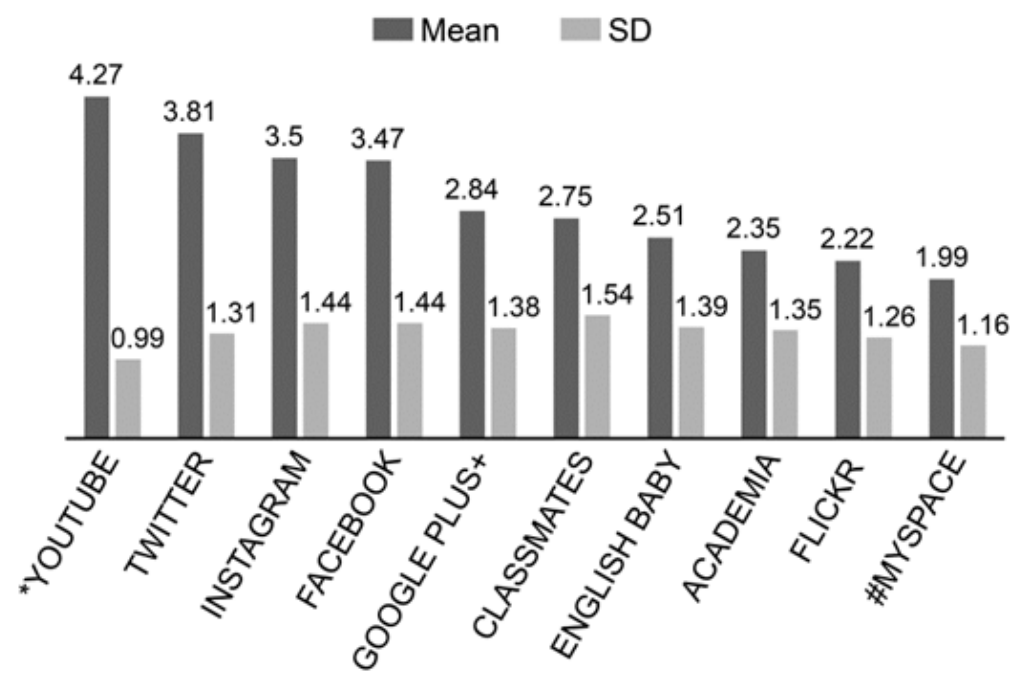

Figure 1. Descriptive statistics for participants' experience in SNS tools

Note. The mean score $>3$ indicates participants' average experience, while * indicates very good experience and \# indicates poor experience in the SNS tools. The overall mean score for participants' experience in the use of SNS tools was 2.97, which indicates overall average experience.

\subsection{Attitudes of EFL Students toward the effectiveness of SNS}

For the $2^{\text {nd }}$ research question, 10 Likert-scale items were administered to identify participants' attitudes toward SNS effectiveness. The descriptive analysis results in Figure 2 indicated that participants generally had an overall positive attitude toward SNS ( $\mathrm{m}=3.46, \mathrm{SD}=1.39$ ), most specifically, for communication and learning purposes. Most of the participants strongly expressed their desire and confidence to use SNS in their language learning.

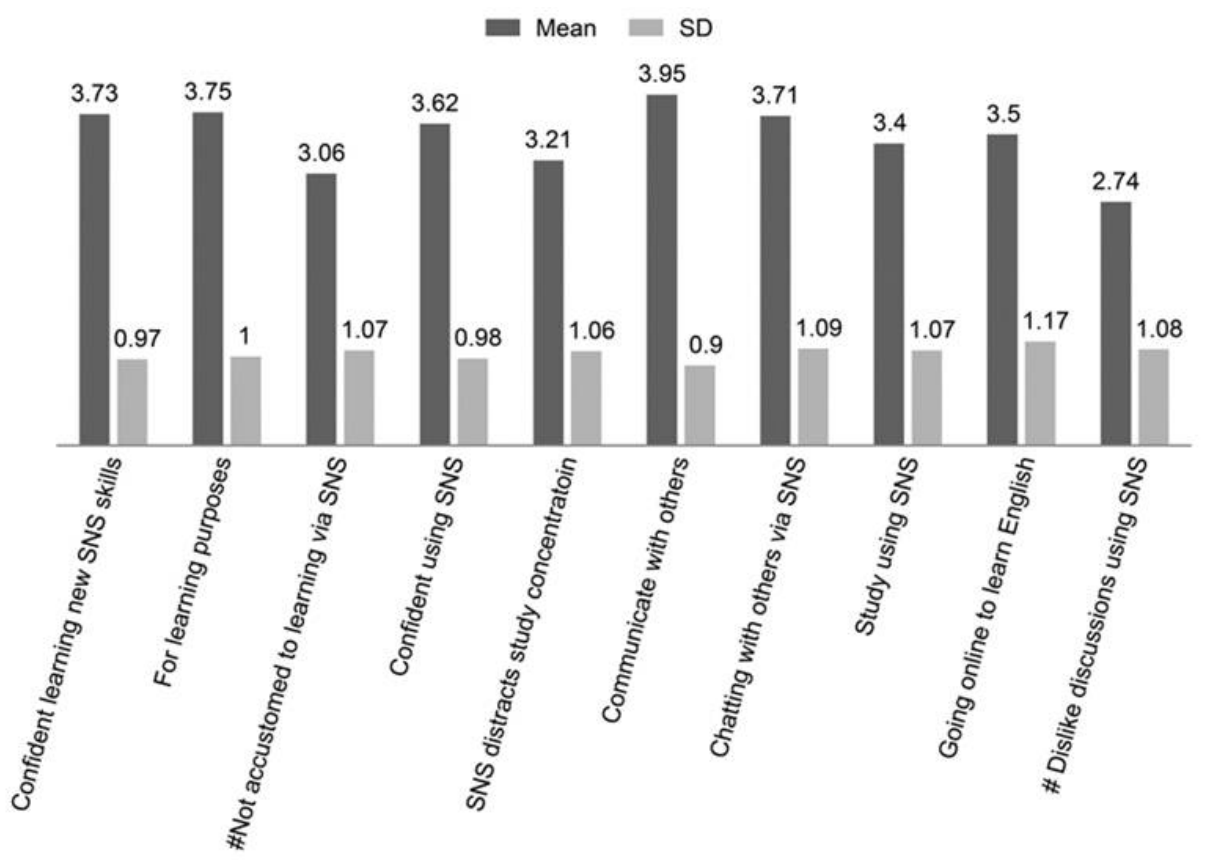

Figure 2. The descriptive statistics results for participants' attitudes toward social network sites (SNS)

Note. The mean score $>3$ indicates participants' positive attitude, while \# indicates neutral attitude. The overall mean score was 3.46 with the SD of 1.39 , which indicates a general positive consensus of participants' attitudes toward SNS. 


\subsection{Perceptions of EFL Students toward the Effectiveness of SNS}

For the $2^{\text {nd }}$ research question, 20 Likert-scale items were also administered to identify participants' perceptions toward SNS effectiveness. The descriptive statistical analysis results (see Figure 3) indicated that participants had overall positive perceptions toward SNS $(\mathrm{m}=3.94, \mathrm{SD}=0.96)$. Among all the items, most of the participants strongly agreed that SNS served as a good channel to learn more about foreign languages and cultures, thus allowing a greater access to direct information from English-speaking countries and making language learning more fun.

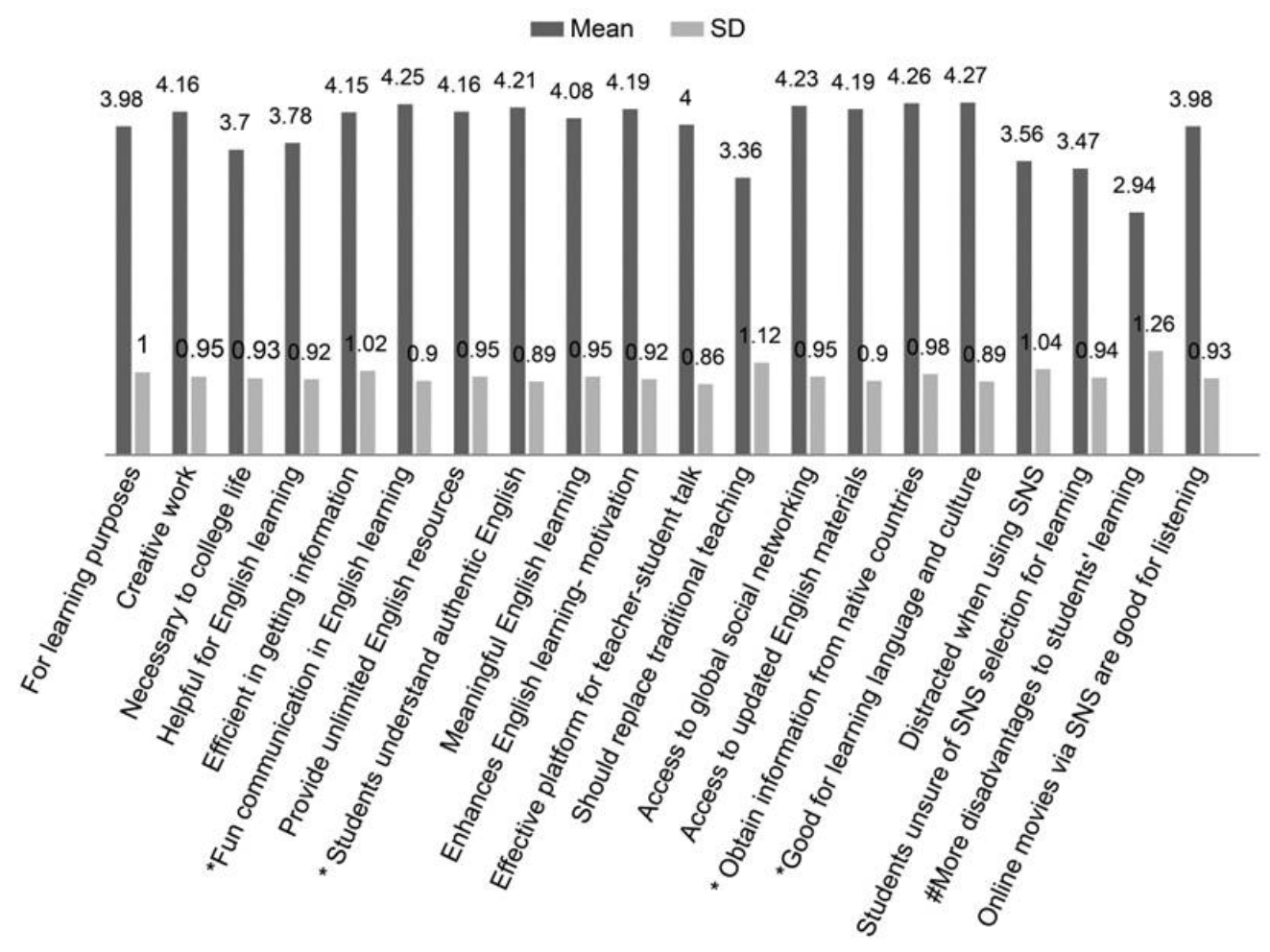

Figure 3. The descriptive statistics results for participants' perceptions toward social network sites (SNS)

Note: The mean score $>3$ indicates participants' positive agreement, * indicates strong agreement, and \# indicates neutral agreement. The overall mean score was 3.94 with the SD 0.96, which indicates a general positive consensus of participants' perceptions toward SNS.

\subsection{Expectations of EFL Students toward the Effectiveness of SNS}

For the $2^{\text {nd }}$ research question, participants also responded to 20 Likert-scale items to identify their expectations toward SNS effectiveness, which were subsequently illustrated in Figure 4 using results from descriptive statistical analysis. Results showed overall positive expectations toward SNS $(\mathrm{m}=3.84, \mathrm{SD}=0.99)$. Most of the participants strongly agreed that SNS could be used more often for their language skills improvement and opportunities for interactive activities. 


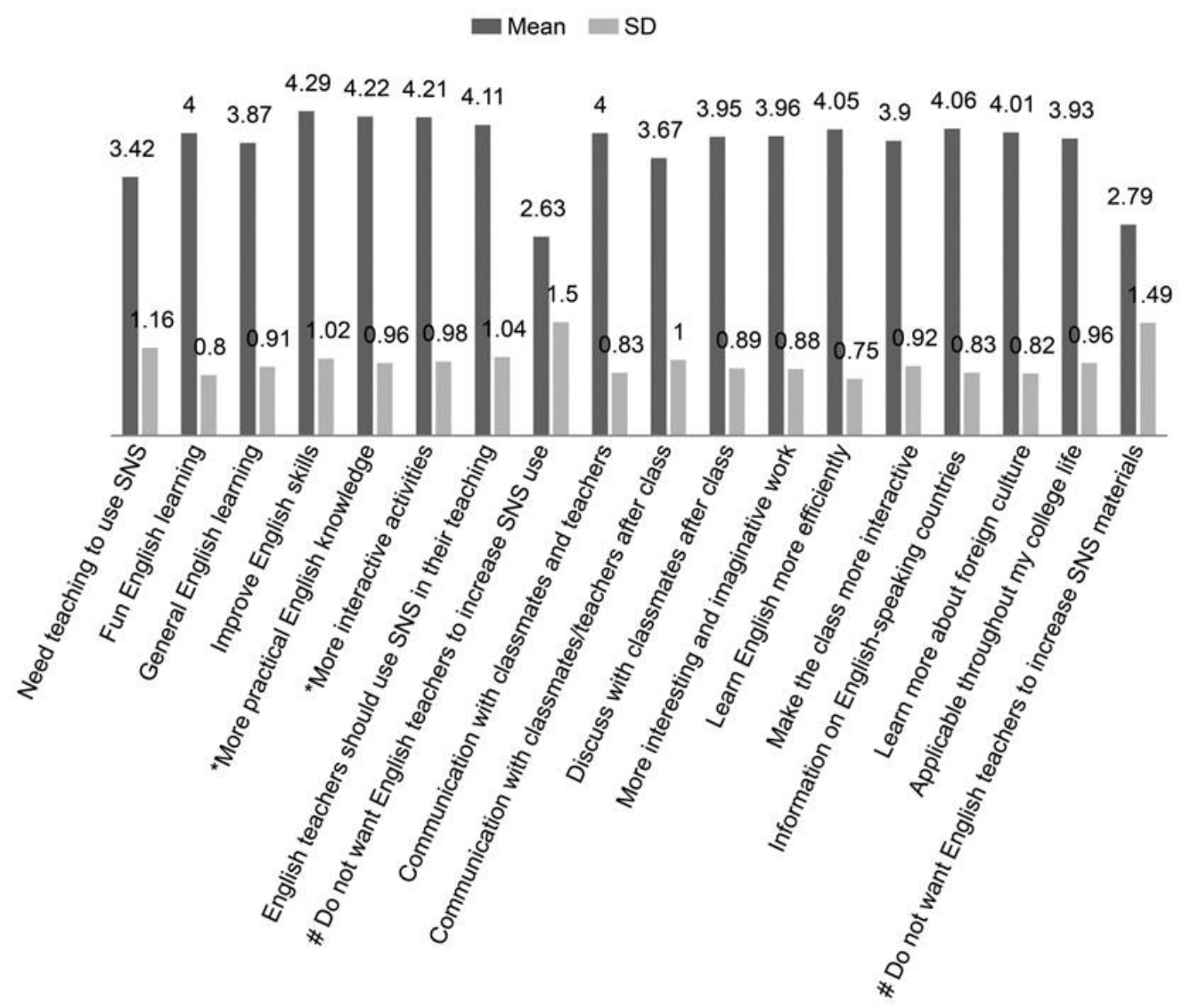

Figure 4. The descriptive statistics results for participants' expectations toward social network sites (SNS)

Note: The mean score $>3$ indicates participants' positive agreement, * indicates strong agreement, and \# indicates neutral agreement. The overall mean score was 3.84 with the SD 0.99 , which indicates a general high and positive consensus of participants' expectations toward SNS use in English teaching.

\subsection{The Relationship between EFL Students' Experience, Attitudes, Perceptions, and Expectations toward the Effectiveness of SNS}

To answer the $3^{\text {rd }}$ research question, Pearson Correlation Coefficients were employed. The data analysis in Figure 5 revealed that the correlations between experience and attitudes $(\mathrm{r}=.221, \mathrm{p}=.025)$, and correlations between experience and expectations $(\mathrm{r}=.218, \mathrm{p}=.027)$ were statistically significant. Furthermore, results showed that the correlations between attitudes and perceptions $(\mathrm{r}=.463, \mathrm{p}=.000)$, attitudes and expectations $(\mathrm{r}$ $=.508, \mathrm{p}=.000)$, and perceptions and expectations $(\mathrm{r}=.796, \mathrm{p}=.000)$ were statistically significant. However, data analysis showed that experience did not significantly correlate with perceptions $(r=.086, p=.393)$. 


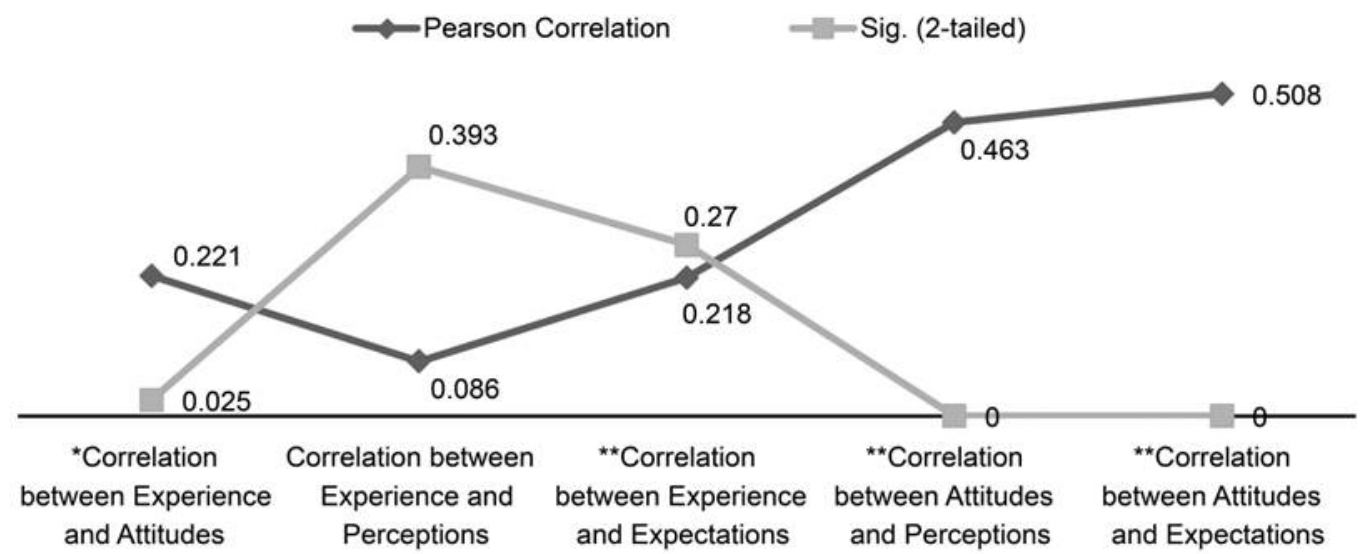

Figure 5. Results from the correlation coefficient analysis for participants' variables in the use of SNS for English learning

Note: $\mathrm{N}=103, *$ means the correlation is significant at the 0.05 level (2-tailed), and $* *$ means the correlation is significant at the 0.01 level (2-tailed).

A multiple regression analysis was performed to determine if the model of the three variables (i.e., attitudes, perceptions, and expectations toward SNS) predicting the variable (experience in SNS) was statistically significant: The model was significant at the 0.05 level, $\mathrm{R} 2=.093$, adjusted $\mathrm{R} 2=.064, \mathrm{~F}(3,97)=3.296, \mathrm{p}=.024$ (Table 2). The only significant predictor was expectations. The analysis of variance of the model is presented in Table 3. The standardized Beta coefficients in Table 4 provide a contribution measurement of each variable to the model.

Table 2. Multiple regression analysis summary of the three-variable model

\begin{tabular}{lllll}
\hline Model & $\mathrm{R}$ & R Square & Adjusted R Square & Std. Error of the Estimate \\
\hline 1 & $.304^{\mathrm{a}}$ & 0.093 & 0.064 & 8.2066 \\
\hline
\end{tabular}

Table 3. Analysis of variance for the participants' variables

\begin{tabular}{lllllll}
\hline Model & & Sum of Squares & df & Mean Square & F & Sig. \\
\hline \multirow{3}{*}{1} & Regression & $665.917^{\mathrm{a}}$ & 3 & 221.972 & 3.296 & $.024^{\mathrm{b}}$ \\
& Residual & $6532.776^{\mathrm{a}}$ & 97 & 67.348 & & \\
& Total & 7198.693 & 100 & & & \\
\hline
\end{tabular}

${ }^{\mathrm{a}}$ indicates the dependent variable: Experience.

${ }^{\mathrm{b}}$ indicates the predictors: (Constant), Attitudes, Perceptions, Expectations.

Table 4. Regression coefficients analysis for the variables

\begin{tabular}{|c|c|c|c|c|c|c|}
\hline \multirow{2}{*}{\multicolumn{2}{|c|}{ Model }} & \multicolumn{2}{|c|}{ Unstandardized Coefficients } & \multirow{2}{*}{$\begin{array}{l}\text { Standardized } \\
\text { Coefficients }^{\mathrm{a}} \\
\text { Beta }\end{array}$} & \multirow[t]{2}{*}{$\mathrm{t}$} & \multirow[t]{2}{*}{ Sig. } \\
\hline & & $\overline{\mathrm{B}}$ & Std. Error & & & \\
\hline \multirow{4}{*}{1} & (Constant) & 17.338 & 5.848 & & 2.965 & .004 \\
\hline & Attitudes & .244 & .165 & .168 & 1.486 & .140 \\
\hline & Perceptions & $-.178-$ & .104 & $-.275-$ & -1.708 & .091 \\
\hline & Expectations & .258 & .120 & .355 & 2.147 & .034 \\
\hline
\end{tabular}

${ }^{\mathrm{a}}$ indicates the dependent variable: Experience. 


\section{Conclusion}

The findings revealed that the participants had average overall SNS experience, and they were most experienced to Youtube, Twitter, and Instagram respectively. The findings also indicated that participants had overall positive attitudes, perceptions, and expectations toward SNS. In addition, the correlations between experience and attitudes, and experience and expectations were statistically significant. Data analysis also showed that the correlations between attitudes and perceptions, attitudes and expectations, and perceptions and expectations were statistically significant. However, experience did not significantly correlate with perceptions. The findings also indicated that the model of the three variables (attitudes, perceptions, and expectations toward SNS) predicting the variable (experience in SNS) was statistically significant: The significant predictor was expectations.

The study findings indicated that EFL students in the Saudi higher education institutions have positive experience, attitudes, and expectations toward SNS. The majority of participants had a good experience in YouTube, Twitter, and Instagram which have been proved to develop EFL listening and writing in particular. Most of the participants strongly expressed their desire and confidence to use SNS in their language learning. They also strongly agreed that SNS help them learn EFL and its culture, as well as make language learning more fun. Therefore, SNS should be wisely and effectively utilized insdie \& outside the classroom.

EFL students should be provided with SNS integration opportunities throughout their learning experience through the use and experimentation of different SNS tools as a fundamental component of their EFL learning process. Furthermore, technical support must be available to facilitate students' adoption and integration of SNS and to overcome any technical difficulties that they might encounter before and during the integration process. The learning environment should also be equipped with all necessary equipment (e.g., computers, internet access, and labs) in order to promote EFL students' integration of SNS in their learning process.

\subsection{Limitations and Suggestions for Future Study}

The study results suggest that further research on SNS in EFL learning should be considered. This study examined EFL students' experience, attitudes, perceptions, and expectations toward SNS in English language teaching. Future research should also examine EFL students' learning styles and their adoption and integration of SNS tools as well. The ICT model was adopted as a theoretical framework for investigating the relationship between the four constructs (experience, attitudes, perceptions, and expectations). Future research should employ other models that investigate SNS integration in educational settings. Furthermore, this study used a quantitative approach to investigate EFL students' experience, attitudes, perceptions, and expectations toward SNS. Future research should employ a qualitative approach as well in order to explicate further this issue. Acknowledge the limitations of your research, and address alternative explanations of the results.

\section{References}

Alm, A. (2006). CALL for autonomy, competence, and relatedness: Motivating language learning environments in Web 2.0. The JALT CALL Journal, 2(3), 29-38.

Bibby, S. (2011). Do students wish to 'Go Mobile'?: An investigation into student use of PCs and cell phones. International Journal of Computer-Assisted Language Learning and Teaching (IJCALLT), 1(2), 43-54. https://doi.org/10.4018/ijcallt.2011040104

Blattner, G., \& Fiori, M. (2009). Facebook in the language classroom: Promises and possibilities. International Journal of Instructional Technology \& Distance Learning, 6(1), 17-28.

Boyd, D. M., \& Ellison, N. B. (2007). Social network sites: Definition, history, and scholarship. Journal of Computer-Mediated Communication, 13(1), 11. https://doi.org/10.1111/j.1083-6101.2007.00393.x

Burke, S., Snyder, S., and Rager, R.C. (2009). An Assessment of faculty usage of YouTube as a teaching resource. The Internet Journal of Allied Health Sciences and Practice, 7(1).

Canale, M., \& Swain, M. (1980). Theoretical bases of communicative approaches to second language teaching and testing. Applied Linguistics, 1(1), 1-47. https://doi.org/10.1093/applin/i.1.1

Chartrand, R. (2012). Social networking for language learners: Creating meaningful output with Web 2.0 tools. Knowledge Management \& E-Learning: An International Journal, 4(1), 97-101.

Clarkson, K. (2013). Usage of social network sites amongst university students. Munich, Germany: GRIN Verlag.

Duffy, P. (2011). Facebook or faceblock: Cautionary tales exploring the rise of social networking within tertiary education. In C. McLoughlin, \& M. Lee (Eds.), Web 2.0-based E-learning: Applying social informatics for 
tertiary teaching (pp. 284-300). Hershey, PA: Information Science Reference. https://doi.org/10.4018/978-1-60566-294-7.ch015

Duman, G., Orhon, G., \& Gedik, N. (2015). Research trends in mobile assisted language learning from 2000 to 2012. ReCALL, 27(2), 197-216. https://doi.org/10.1017/s0958344014000287

Eagly, A. H., \& Chaiken, S. (1993). The psychology of attitudes. Forth Worth, TX: Harcourt Brace Jovanovich College Publishers.

Experience. (n.d.). In Cambridge online dictionary. Retrieved from http://dictionary.cambridge.org/dictionary/english/experience

Experience. (n.d.). In Merriam-Webster online dictionary. Retrieved from http://www.merriam-webster.com/dictionary/experience

Grosseck, G., and Holotescu, C. (2008). Can we use Twitter for educational activities? Paper presented at the 4th International Scientific Conference, eLearning and Software for Education, Bucharest, Romania.

Hamilton, R. (2010). YouTube for two: Online video resources in a student-centered, task-based EFL Environment. Contemporary Issues in Education Research, 3(8), $27-32$. https://doi.org/10.19030/cier.v3i8.224

Hogg, M., \& Vaughan, G. (2005). Social Psychology (4th edition). London: Prentice-Hall.

Johnson, B., \& Christensen, L. (2000). Educational research: Quantitative \& qualitative approaches. Boston, MA: Allyn \& Bacon.

Johnson, M. (2010). Students'Attitudes, Perceptions, and Expectations toward Instructional Technology in Higher Education: A Diffusion of Innovations. Bloomington: NY: iUniverse, Inc.

Kabilan, M. K., Ahmad, N., \& Abidin, M. J. Z. (2010). Facebook: An online environment for learning of English in institutions of higher education? Internet and Higher Education, 13(4), 179-187. https://doi.org/10.1016/j.iheduc.2010.07.003

Kho, M. G. W., \& Chuah, K. M. (2012). Encouraging ESL discourse exchanges via Facebook: A study on engineering students. In Innovation: A new opportunity for all. Proceedings of 2nd Innovation Conference and Exposition 2012, (pp. 44-48).

Kikuchi, K., \& Otsuka, T. (2008). Investigating the use of social networking services in Japanese EFL classrooms. The JALT CALL Journal, 4(1), 40-52.

Kukulska-Hulme, A. (2009). Will mobile learning change language learning? ReCALL, 21(2), $157-165$. https://doi.org/10.1017/S0958344009000202

Lai, A., Yeung, Y., \& Hu, J. (2016). University student and teacher perceptions of teacher roles in promoting autonomous language learning with technology outside the classroom. Computer Assisted Language Learning, 29(4), 703-723. https://doi.org/10.1080/09588221.2015.1016441

Liu, M., Abe, K., Cao, M., Liu, S., Ok, D.U., Park, J., ... Sardegna, G. (2015). An analysis of social network websites for language learning: Implications for teaching \& learning English as a Second Language. The CALICO Journal, 32(1), 114-152. https://doi.org/10.1558/cj.v32i1.114-152

Liu, M., Evans, M., Horwitz, E., Lee, S., McCrory, M., Park, J., \& Parrish, C. M. (2013). A study of the use of social network sites for language learning By university ESL students. In M. Lamy, \& K. Zourou (Eds.) Social networking for language education. New York, NY: Palgrave Macmillan. https://doi.org/10.1057/9781137023384_8

Mahmud, M., \& Ching, W. (2012). Facebook. Does it really work for L2 learners. Academic Research International, 3(2), 357-370.

Maio G.R., \& Haddock G. (2009). The Psychology of Attitudes and Attitude Change. SAGE Publications.

Melor, Y., \& Salehi, H. (2012). The effectiveness of Facebook groups on teaching and improving writing: Students' perceptions. International Journal of Education and Information Technologies, 6(1), 87-96.

Michener, H. A., DeLamater, J. D., \& Myers, D. J. (2004). Social Psychology. Australia: Thompson Wadsworth.

Mork, C. (2009). Using Twitter in EFL education. The JALT CALL Journal, 5(3). 41-56.

Myers, D. G. (2004). Myers'Psychology for AP. Seventh Ed. New York, NY: Worth.

Ru-Chu, S. (2011). Can Web 2.0 technology assist college students in learning English writing? Integrating 
"Facebook" and peer assessment with blended learning. Australasian Journal of Educational Technology, 27(5), 829-845.

Simonson, M. (1995). Instructional technology and attitude change. In G. J. Aglin (Ed.). Instructional Technology: Past, Present, and Future. Englewood, CO: Libraries Unlimited, pp. 365-373.

Swanson, R. A., \& Holton, E. F. (1997). Human resource development research handbook. Linking research and practice. San Francisco, CA: Berrett-Koehler Publishers, Inc

Vural, O. F. (2015). Positive and negative aspects of using social networks in higher education: A focus group study. Educational Research and Reviews, 10:8, pp. 1147-1166. http://dx.doi.org/10.5897/err2015.21.3.44

Wang, S., \& Vasquez, C. (2012). Web 2.0 and second language learning: What does the research tell us? The CALICO Journal, 29(3), 412-430. https://doi.org/10.11139/cj.29.3.412-430

Yunus, M., Salehi, H., \& Chenzi, C. (2012). Integrating social networking tools into ESL writing classroom: Strengths and weaknesses. English Language Teaching, 5(8), 42-48. https://doi.org/10.5539/elt.v5n8p42

\section{Copyrights}

Copyright for this article is retained by the author(s), with first publication rights granted to the journal.

This is an open-access article distributed under the terms and conditions of the Creative Commons Attribution license (http://creativecommons.org/licenses/by/4.0/). 